\title{
$\operatorname{arCOS} D E S I G N$
}

\section{A disciplina na sala de aula: arquitetura e design como afirmação de concepções de ensino e aprendizagem}

Ricardo Artur Carvalho (ESDI/UERJ, Brasil)

rartur@esdi.uerj.br

Rua Evaristo da Veiga, 95, Lapa

Rio de Janeiro, RJ. CEP: 20031-040

Jackeline Lima Fabiarz (PUC-Rio, Brasil)

jackeline@puc-rio.br 


\title{
A disciplina na sala de aula: arquitetura e design como afir- mação de concepções de ensino e aprendizagem
}

Resumo: O artigo baseia-se numa tese de doutorado e discute o papel das salas de aula no ensino do design. Assume-se uma abordagem interdisciplinar e argumenta-se contra as salas de aula que reproduzem modelos disciplinares. Aborda-se a gênese da sala de aula moderna e a manutenção das organizações espaciais à despeito das concepções pedagógicas. Conclui-se sobre a importância de se analisar as formas de uso e apropriação desses ambientes a partir de práticas e interações concretas em consonância com o projeto pedagógico.

Palavras-chave: interdisciplinaridade, educação, arquitetura

\section{The discipline in classroom: architecture and design as affir- mation of teaching and learning conceptions}

\begin{abstract}
The paper is based on a doctorate thesis and discusses the role of classrooms in design education. It assumes an interdisciplinary approach, it argues against the classrooms as reproductions of disciplinary models. It encompasses the modern classroom genesis and the spatial organization maintenance despite pedagogical conceptions. As conclusion it defends the importance of analyzing the concrete forms of spatial use and appropriation in consonance with the pedagogical project.
\end{abstract}

Key words: interdisciplinarity, education, architecture. 


\section{Introdução}

Este artigo é baseado na tese de doutorado intitulada "Olhares sobre o ensino do projeto em Design: gêneros e interações em espaços de ensino e aprendizagem" (CARVALHO: 2012). A pesquisa abordou as formas características assumidas nas aulas de projeto dentro do curso de graduação em Design da PUC-RIO e busca entender como os espaços e recursos materiais influenciam as práticas de ensino e aprendizagem e como seriam percebidos pelos alunos de design. No presente texto, apresentamos parte do referencial e a consequente reflexão que fundamentou parte da pesquisa.

De modo a contextualizar o ponto de vista assumido na pesquisa e sua consequente influência sobre a formulação das questões norteadoras e subsequente interpretação dos dados, cabe ressaltar que adotamos como pressuposto o caráter interdisciplinar do Design. Concordamos, pois, com o entendimento da professora Rita Couto (2007) ao entender a vocação interdisciplinar do campo na medida em que concilia diferentes conhecimentos (científicos, empíricos e intuitivos) oriundos de diferentes áreas. Também assumimos o caráter tecnológico do campo, que de acordo com a autora (COUTo, 2007 p.51) diz respeito à finalidade do Design não se restringir apenas à produção de conhecimento, mas à aplicação prática seja na produção ou comercialização de bens ou serviços.

Portanto, é a partir de uma perspectiva interdisciplinar que observamos o ensino de projeto, disciplina que, de acordo com Izabel Oliveira (2009), constitui o eixo curricular de diversos cursos de graduação no país. E ao lançarmos o olhar sobre a sala de aula de projeto colocamos a seguinte a questão: afinal, como são pensados e utilizados estes espaços e recursos? De que maneiras refletem os projetos pedagógicos e as práticas dos agentes?

A pergunta é influenciada pelos estudos do historiador Roger Chartier em sua abordagem sobre a história da leitura ao afirmar que "leitura é sempre uma prática encarnada em gestos, em espaços, em hábitos" (Chartier: 1999, p.13). Com isso o historiador contraria uma noção de leitura abstrata e meramente intelectual ao contextualizá-la no tempo e no espaço.

Em uma perspectiva semelhante, Jean Marie Goulemot (1996) situa o leitor em relação ao texto pelos aspectos fisiológicos, históricos e intertextuais. Para Goulemot (1996:107), “a leitura é sempre produção de sentido” na qual o leitor e o texto sofrem o impacto do corpo, da postura, da história pessoal e coletiva, e finalmente, da biblioteca, ou seja, dos demais textos que dialogam com o leitor e o texto. Para o autor, a intertextualidade é um elemento constituinte da leitura e por isso permeia a construção de sentidos do texto.

Para ambos os autores, a leitura não é apenas uma atividade de decodificação e, muito menos, algo puramente intelectual e individual, mas uma 
prática social que pressupõe interações em ambos tanto no que diz respeito à mente quanto ao corpo. Na esfera mental a interação se dá por meio da intertextualidade e na esfera corporal a interação se dá com os elementos materiais (tipografia, condições de luz, conforto, ambiente, etc.). Assim, ao traduzirmos as ideias dos autores para as situações de ensino e aprendizagem, poderíamos igualmente afirmar que as práticas pedagógicas também se encarnam em gestos, espaços e hábitos.

Se pensarmos no ensino como prática, devemos contemplar a estreita relação entre educação, design e arquitetura. A influência direta dos espaços sobre as práticas e vice-versa, uma vez que a atividades de ensino e aprendizagem não ocorrem fora de contexto. Nesse sentido, compreendemos a importância do estudo lembrarmos as palavras do pesquisador de educação Juarez Dayrell de que "o espaço arquitetônico da escola expressa uma determinada concepção educativa" (DAYRELL: 1996, p.147).

Ao questionarmos sobre a relação entre os espaços de ensino e as práticas pedagógicas apontamos para um aspecto que é frequentemente subvalorizado nos projetos de cursos de graduação em Design: a integração entre projeto pedagógico em consonância com a concepção dos espaços de ensino. Em geral o planejamento pedagógico se dá de maneira separada do planejamento de infraestrutura e, quando se relacionam, se dão mais por tangência dos que por uma efetiva integração. Acreditar que a concepção de sala de aula é neutra, isenta de posições ideológicas e que pode servir indistintamente a qualquer propósito pode ser um grande equívoco. Os modelos de sala de aula costumam pautar-se por uma concepção disciplinar de conhecimento e refletem tanto os processos de controle sociais como também de divisão dos saberes que marcaram a sociedade moderna.

\section{Saberes disciplinares}

(...)Quando me chamam de distinto intelectual eu digo: não! Eu não sou um intelectual! Os intelectuais são os que divorciam a cabeça do corpo. Eu não quero ser uma cabeça que rola por aí! Eu sou uma pessoa! Sou cabeça, corpo, sexo, barriga, tudo! Mas não um intelectual, esse personagem abominável! Como dizia Goya: "A razão cria monstros”. Eduardo Galeano, 2011

A dissociação estabelecida entre os saberes é resultante de um longo processo histórico, mas que se acentua principalmente no século xIx. De acordo com Sommerman (2006), há rupturas cosmológicas, antropológicas e epistemológicas que modificaram o pensamento ocidental a partir da Idade Média, 
movendo-o de uma tendência única e dominante, apoiada pelo pensamento de Platão, para um pluralismo epistemológico, favorecido pela introdução da razão aristotélica no século XII. Para o autor, a retomada de Aristóteles permitiu a separação entre fé e contemplação na teologia e, posteriormente, entre fé e razão, favorecendo o desenvolvimento do racionalismo moderno. O racionalismo ganha uma nova forma no século XVII com o pensamento cartesiano, que afirma uma razão que antecede a experiência, pois esta poderia ser enganosa. Ao mesmo tempo, há o desenvolvimento do empirismo, que afirma a razão não pode preceder a experiência. Ao longo dos séculos XIX e XX as duas correntes geraram diferentes abordagens epistemológicas, novas ciências e separações disciplinares, levando aos saberes fragmentados e especializados.

Diante de um pensamento disciplinar que cada vez mais dissocia-se em áreas de conhecimento hiperespecializadas, corre-se o risco da desintegração dos saberes, do não reconhecimento da complexidade que envolve os objetos de pesquisa e do aprofundamento de dualidades como teoria/prática, lógica/ intuição entre outras. Nesse sentido, as palavras de Galeano parecem ecoar as demandas contemporâneas por saberes mais integrados, complexos e ligados entre si, como também advoga Edgar Morin (2002).

Para estudar a formação dos modelos de sala de aula, optamos portanto por compreender o papel da disciplina tanto na sociedade como na formação escolar. Nesse sentido elegemos a obra do filósofo Michel Foucault, Vigiar e Punir, a fim de observar a formação do que ele compreende como "sociedade disciplinar". Esse é o termo empregado pelo autor para se referir às mudanças operadas na Europa durante os séculos XVII e XVIII que estabeleceram as bases para as mudanças científicas dos séculos XIX e XX.

\subsection{Estratégias disciplinares}

Embora em Vigiar e Punir (Foucault, 2007) o interesse de Foucault se concentre na história da instituição prisão, o filósofo identifica os diversos mecanismos disciplinares em diferentes instituições, como o exército, a escola, hospitais, fábricas e oficinas, além dos recursos das ações controladas pelo Estado como a quarentena. Nesse sentido, ele mostra as transformações ocorridas na sociedade no sentido de tornar os indivíduos, mais dóceis e produtivos. As estratégias descritas por Foucault na sociedade disciplinar dizem respeito aos mecanismos de docilização dos corpos, adestramento e panoptismo.

Foucault reconhece que a disciplina não surge nos séculos XVII e XVIII, mas destaca que nesse período houve um aprimoramento minucioso nas técnicas disciplinares. Para o autor, tais técnicas fizeram que o poder disciplinar operasse de maneira tão difusa através de múltiplos sistemas que se tornaram imperceptíveis. Essa diferença é fundamental na análise do filósofo pois 
modifica um exercício explícito do poder para uma forma desapercebida e insidiosa, que ele compara com o nível subatômico, aquilo que chama de microfísica do poder.

Segundo Foucault (2007), o mecanismo da docilização dos corpos ocorreria mediante quatro estratégias:

1. A arte das distribuições diz respeito às técnicas de isolamento espacial, quadriculamento, localização funcional e posicionamento na fila, empregadas para controlar os grupos e indivíduos. Essa estratégia introduz uma abordagem celular de controle, tais como a medida das quantidades, a análise dos movimentos, a taxinomia que permitiriam a introdução do problema do singular e do múltiplo.

2. O controle das atividades emprega o horário, a elaboração temporal do ato, a correlação entre o corpo e o gesto, a articulação corpo-objeto e a utilização exaustiva para tornar as tarefas mais efetivas. O controle das atividades introduziu os processos e exigências orgânicas do corpo, que passa a ser visto como organismo.

3. A organização das gêneses utiliza a segmentação de etapas, sequencias, ciclos e séries de maneira a submeter os indivíduos a um processo de formação segmentada, segundo um grau crescente de complexidade. A organização das gêneses introduz o problema da acumulação do tempo e fomenta a perspectiva do progresso e formação "genética" dos indivíduos.

4. A composição das forças utiliza o corpo singular em relação a outros corpos, ao tempo e também à submissão de um comando claro. Essa estratégia introduz a questão combinatória, buscando a eficiência mediante o uso de táticas.

De um modo geral, Foucault (2007) reconhece nessas estratégias de controle do corpo a formação de novas formas de individualidade, pois introduzem maneiras minuciosas de tornar os corpos dóceis e eficientes. Segundo o filósofo há uma mudança na visão do corpo, que se torna com estas técnicas manipulável, treinável, adequável às diferentes exigências.

Da mesma maneira, as instituições como hospitais, quarteis, oficinas e escolas acompanham e se adequam a estas formas de controle: na escola, por exemplo a separação dos alunos por classes, a divisão de horários, a elaboração dos gestos caligráficos, a postura, o estabelecimento de ciclos, ordens, rotinas e grupos promovem grandes transformações no ensino. Mas essas estratégias não afetam apenas uma mudança de comportamento, são acompanhadas de mudanças na arquitetura, na divisão dos espaços, no mobiliário e nas ferramentas de uso cotidiano. 
Ao evidenciar o controle exercido sobre os corpos, Foucault aponta para os princípios disciplinares que guiaram o urbanismo, a arquitetura e o design moderno: a organização funcional e especializada dos espaços, planejados para tornar as atividades mais eficazes mediante o controle e obediência.

Além do controle do corpo, Foucault (2007) também apresenta o mecanismo do adestramento, que emprega as seguintes estratégias:

1. A vigilância hierárquica: estabelece grupos hierárquicos que vigiam e reportam às instâncias superiores, cria uma estrutura em que se favoreça o controle e a sensação de controle.

2. A sanção normalizadora; constitui-se pela combinação entre pequenos mecanismos penais, a penalização por descumprimento das normas, o castigo como forma de redução de desvios; a punição num sistema de gratificação-sanção e a divisão segundo classificações de recompensa ou punição. Dessa forma estabelece a norma e pune os desvios.

3. O exame; emprega técnicas analíticas, submetendo os indivíduos à inspeção, registro e controles cada vez mais constantes.

O adestramento estabelece um poder capaz de vigiar, punir desvios e examinar minuciosamente. Este mecanismo inverte aquilo que Foucault chama de "economia da visibilidade" e coloca os indivíduos em evidência, o que antes destinado apenas aos nobres. Com isso, contribui tanto para a individualização generalizada como para um controle a nível individual que se exerce de maneira mais forte sobre aqueles que estão submetidos: as crianças são mais individualizadas que os adultos, os doentes mais que os saudáveis etc.

O terceiro mecanismo apresentado por Foucault é o panoptismo. O filósofo aponta o panóptico, prisão modelo idealizada pelo inglês Jeremy Bentham, como símbolo da sociedade disciplinar. O panóptico (Figura 1) é uma construção circular onde todas as celas ficam voltadas para uma torre central. A ideia que guia essa construção é que os presos não se vejam nem vejam os vigias, mas que os vigias possam ver plenamente os presos. A analogia de Foucault diz respeito à manifestação de um poder presente, mas invisível, fruto de uma vigilância constante e desapercebida, no qual os indivíduos sabem-se vigiados sem notar a presença do vigia. 


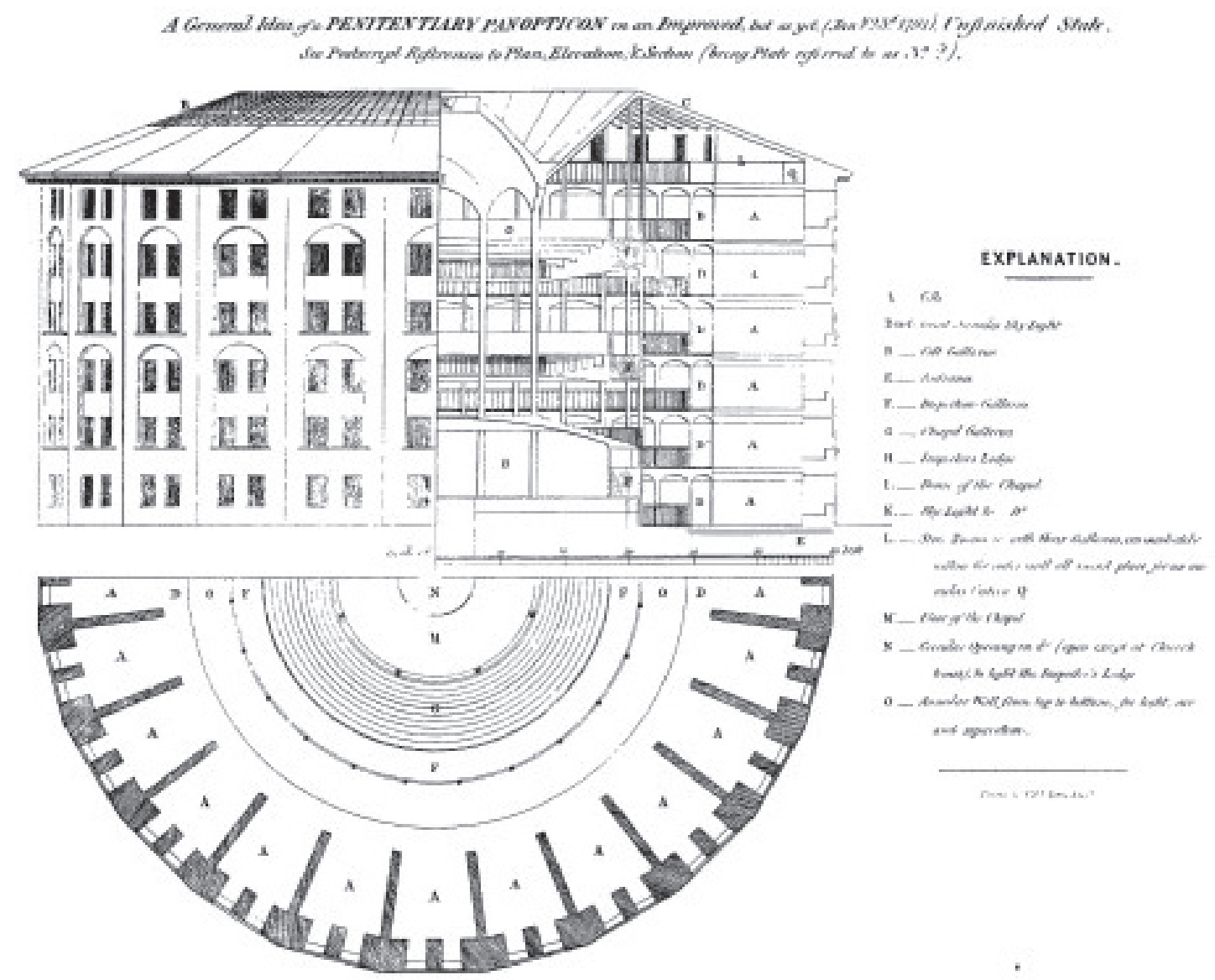

Figura 1. Planta baixa e vista da fachada e corte do Panóptico de Bentham. Fonte: Foucalt, 2007.

Os mecanismos de controle disciplinar conjugados na sociedade não apenas favoreceram o controle dos indivíduos, como permitiram a redução dos castigos físicos e as punições públicas. Em seu lugar, uma forma mais sutil e eficiente de controle tomou lugar, sustentada pelo sentimento de vigilância constante, no qual os próprios indivíduos se autorregulariam. A sociedade disciplinar, segundo Foucault, não depende mais das manifestações evidentes do poder, mas de todo um sistema que o reforça de uma maneira quase imperceptível.

(...)O indivíduo é sem dúvida o átomo fictício de uma representação 'ideológica' da sociedade; mas é também uma realidade fabricada por essa tecnologia específica de poder que se chama a "disciplina". Temos que deixar de descrever sempre os efeitos de poder em termos negativos: ele "exclui", "reprime", "recalca”, “censura”, "abstrai", "mascara”, "esconde”. Na verdade o poder produz; ele produz realidade; produz campos de objetos e rituais da verdade. O indivíduo e o conhecimento 
que dele se pode ter se originam nessa produção. (Foucault: 2007, p. 161)

\section{Disciplina social e disciplina acadêmica}

A disciplina à qual Foucault se refere, não diz respeito às disciplinas acadêmicas, mas às técnicas disciplinares que perpassam diferentes setores da sociedade. Foucault fala das técnicas de controle dos corpos, dos gestos, das ações, do tempo, dos espaços, entre outros elementos, como forma de tornar os indivíduos mais dóceis e eficientes. Porém, é interessante mencionar que tais técnicas também levaram a um processo de individualização, desenvolvendo tecnologias como o exame e o quadriculamento que favoreceram o desenvolvimento das ciências humanas no século XIX e xx.

Se por um lado a disciplina estabeleceu uma forma socialmente opressiva de controle, por outro lado ela introduziu uma série de questões referentes à singularidade, empregando técnicas de minúcia e individuação decisivas para o desenvolvimento da psicologia, pedagogia, psiquiatria e outras ciências. Nesse sentido, Foucault estabelece uma relação íntima entre poder e saber, pois argumenta que as formas de poder estabelecem novas possibilidades de conhecimento que, por sua vez, acabam reafirmando tais estruturas de poder.

A relação entre poder e saber é dinâmica e interdependente, sendo tratada por Foucault como um binômio "saber-poder". Ele exemplifica essa relação com o papel das técnicas inquisitoriais nos séculos XII e XIII para o desenvolvimento das ciências da natureza:

Ora, o que o inquérito político-jurídico, administrativo e criminal, religioso e leigo foi para as ciências da natureza, a análise disciplinar foi para as ciências do homem. Essas ciências com que nossa 'humanidade' se encanta há mais de um século têm sua matriz técnica na minúcia tateante e maldosa das disciplinas e de suas investigações. Estas são talvez para a psicologia, a pedagogia, a psiquiatria, a criminologia, e para tantos outros estranhos conhecimentos, o que foi o terrível poder do inquérito para o saber calmo dos animais, das plantas ou da terra. Outro poder, outro saber. - Foucault: 2007, p.186

É interessante observar que paralelamente ao processo de formação dessa sociedade disciplinar, há um processo de separação e especialização dos saberes que utilizam uma estratégia semelhante: separar, dividir e ordenar para controlar. De tal maneira, como afirma Sommerman (2006), as ciências passaram a se separar e especializar ao longo dos séculos XIX e xx chegando a um nível de hiperespecialização e fragmentação cada vez maior.

Os reflexos do pensamento disciplinar vão além da epistemologia e das práticas institucionais e influenciam também as práticas profissionais na 
concepção dos espaços modernos. O planejamento urbano nos séculos XIX e xx busca disciplinar a cidade e torná-la mais eficiente como no caso de Paris por Haussmann (Figura 2), o Rio por Pereira Passos etc.. A arquitetura moderna também planeja os ambientes de acordo com as funções (Figuras $3 \mathrm{e}$ 4), seguindo a máxima "a forma segue a função", formulada pelo arquiteto americano Louis Sullivan, em 1896 e que se tornou uma espécie de "mantra" funcionalista. O design moderno, por sua vez, também segue esta tendência (Figura 5), seja na Hfg de Ulm onde o funcionalismo era a tônica, seja no discurso sobre o bom design de Dieter Rams. Os objetos pensados segundo essa abordagem devem se tornar eficientes, tanto em relação ao uso como em relação ao seu processo de produção. Mesmo o design gráfico foi profundamente influenciado ao tentar disciplinar a composição tipográfica mediante o uso da grid conforme advoga Josef Müller-Brockmann (Figura 6).

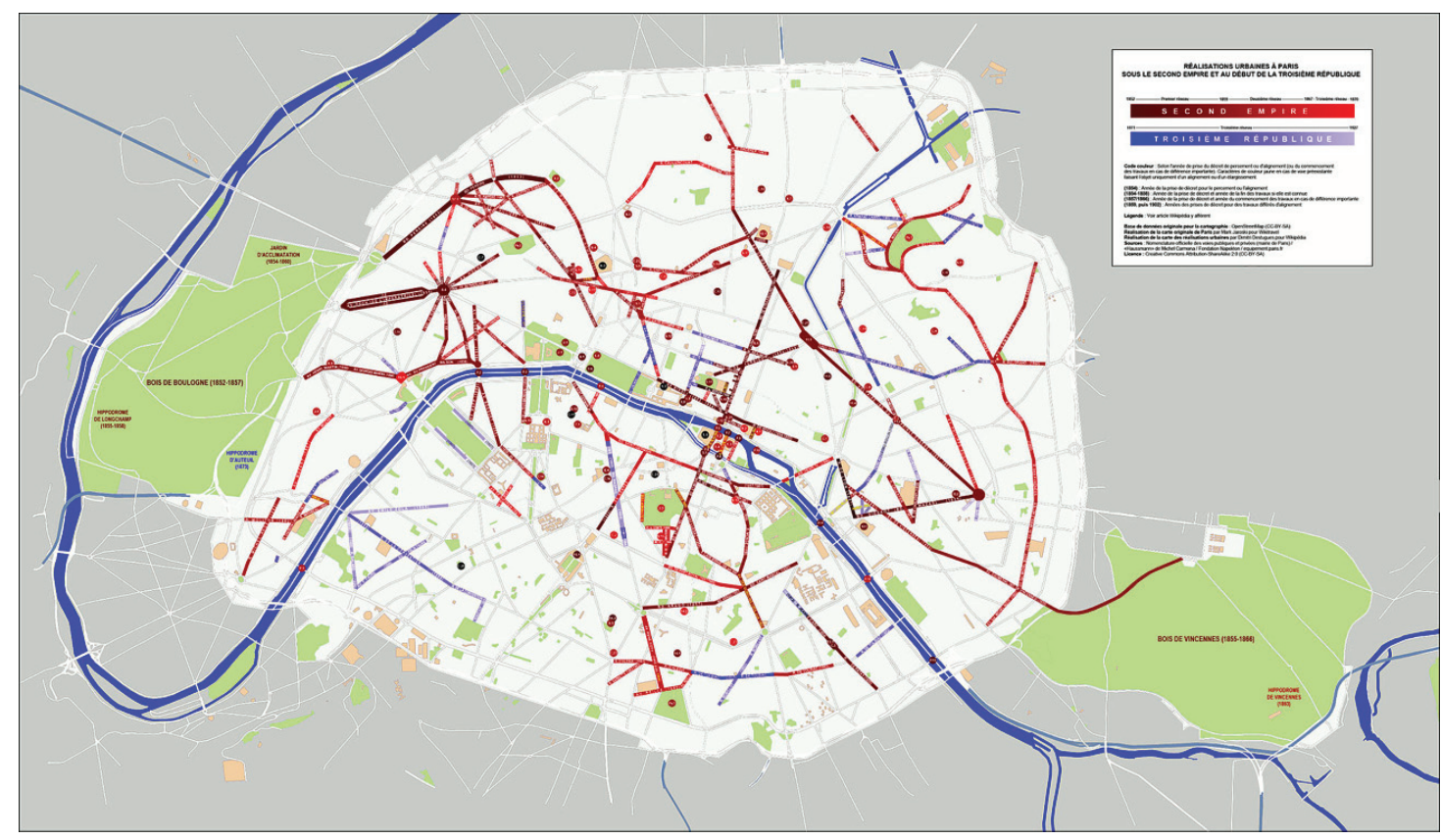

Figura 2. A renovação de Paris no século XIX previa a setorização através dos arrondissements e o alargamento das ruas na forma de boulevards para maior controle das revoltas populares. Fonte: Wikipedia. 


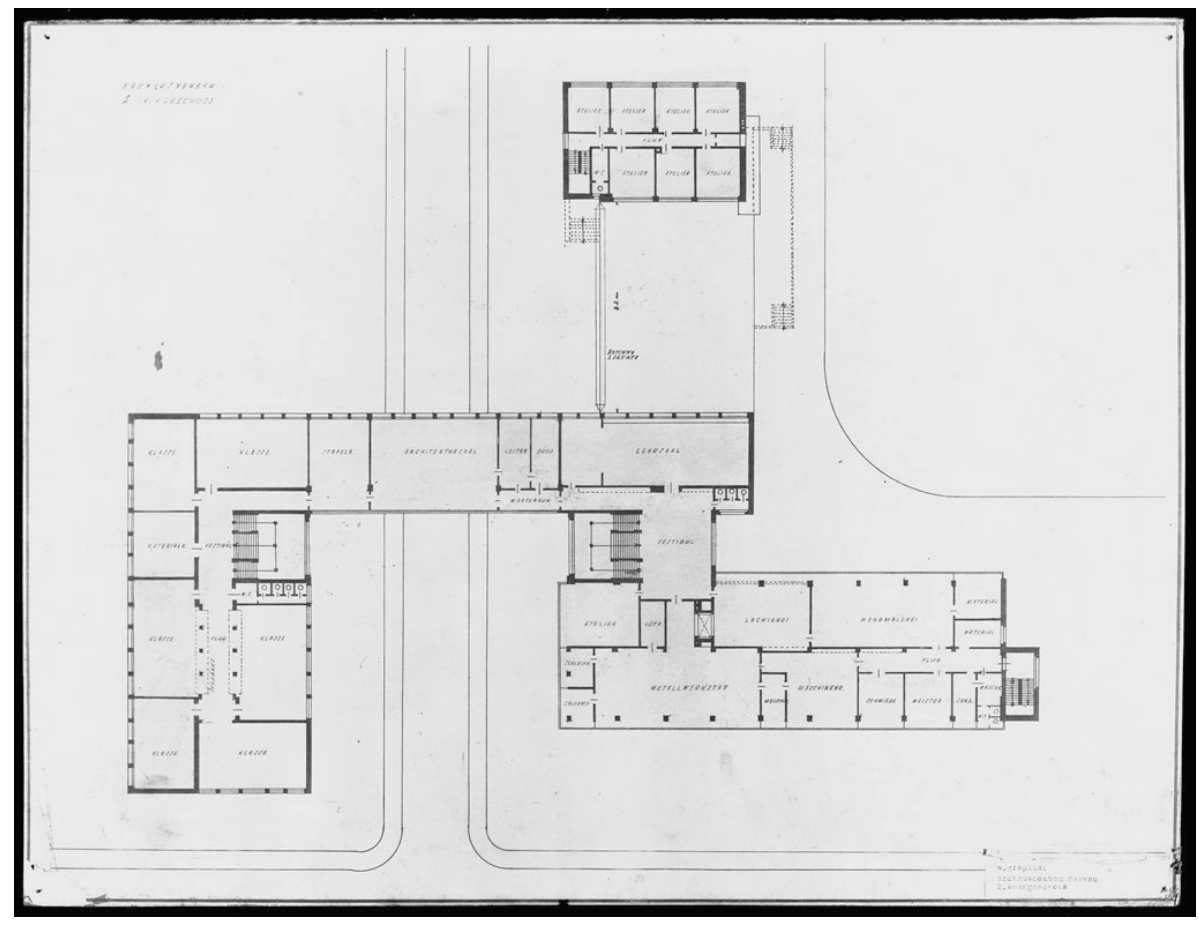

Figura 3. Planta baixa do edifício e setores da Bauhaus em Dessau, 1926, mostra a divisão da escola projetada especialmente para o ensino de design e arquitetura. Fonte: Harvard Art Museums, 2013

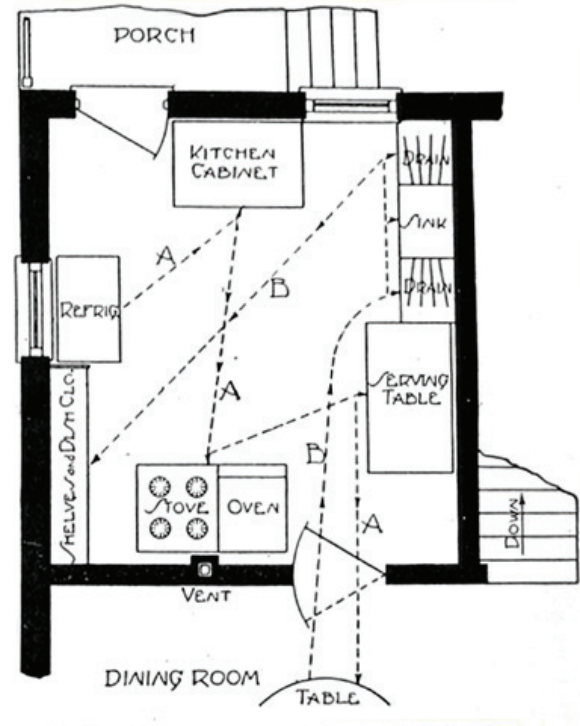

BADLY GROUPED KITCHEN EQUIPMENT

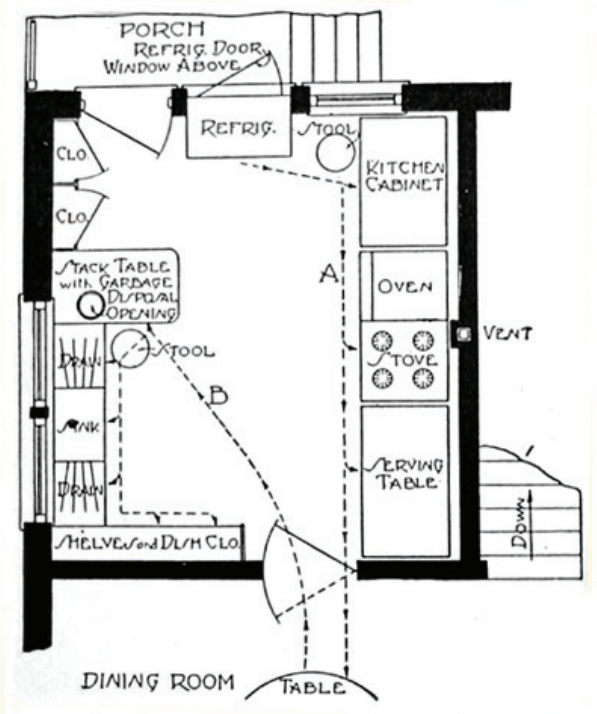

EFFICIENT GROUPING OF KITCHEN EQUIPMENT A. Preparing route. B. Clearing away route.

Figura 4. Planejamento da cozinha eficiente, 1920, por Christine Fredericks, busca a organização racional e funcional para tornar as atividades mais eficientes.

Fonte: DE STEFANI, 2011. 


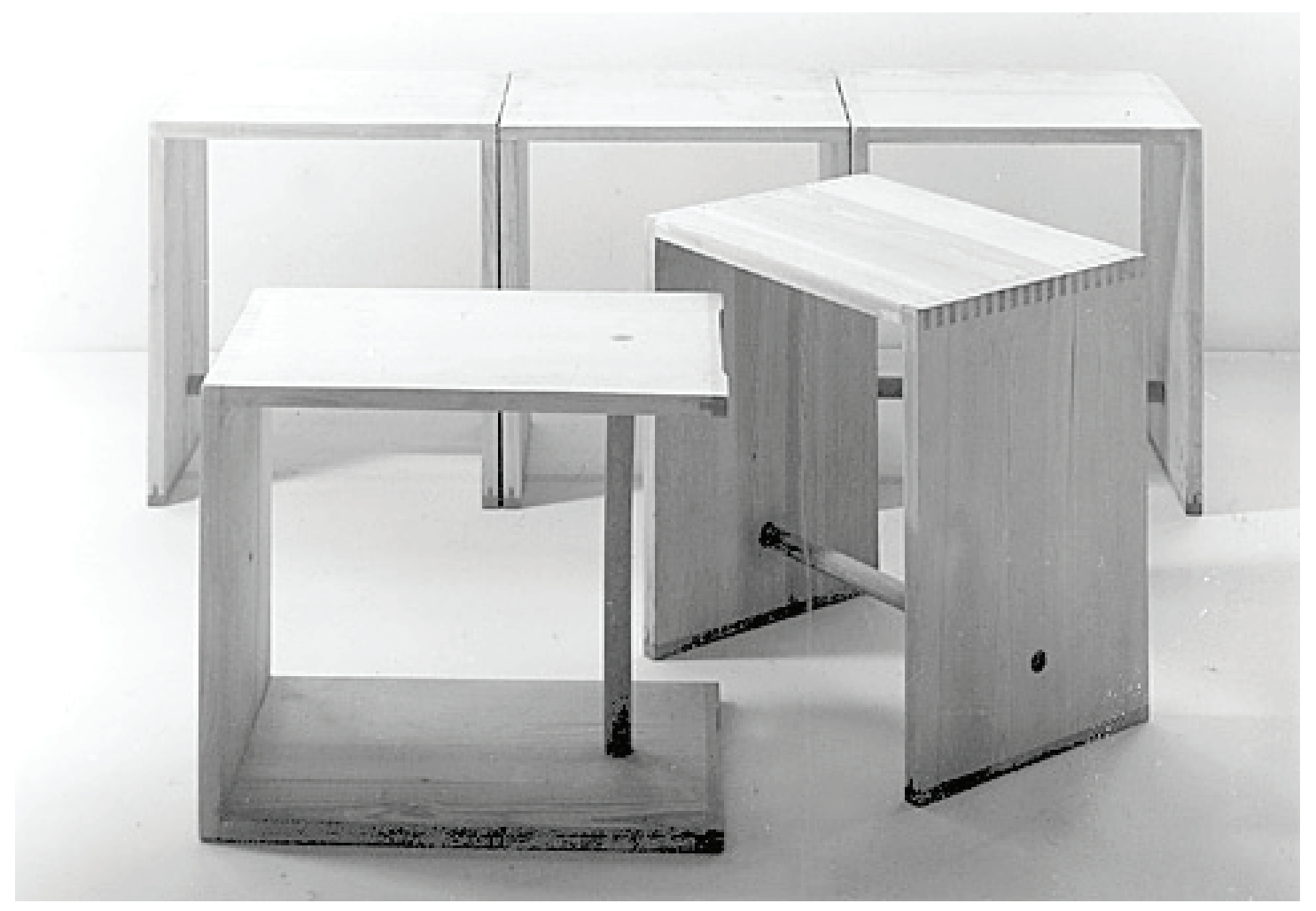

Figura 5. Bancos de Ulm, 1954, servem como estante e mesa de centro, projeto de Max Bill. Fonte: Hfg-Archiv Ulm 2011.

De acordo com Foucault, o poder disciplinar se manifesta de maneira insidiosa na sociedade. Os exemplos acima mostram como as técnicas de controle e a busca por eficiência das atividades permeou tanto os saberes como a sociedade e também seus espaços e objetos. A eficiência, nesse sentido, diz respeito a uma maneira específica de se cumprir as metas desejáveis, no melhor tempo possível, segundo os parâmetros de normalidade. O controle é realizado mediante um complexo sistema de exames, classificações, organizações, distribuições, punições e incentivos. 


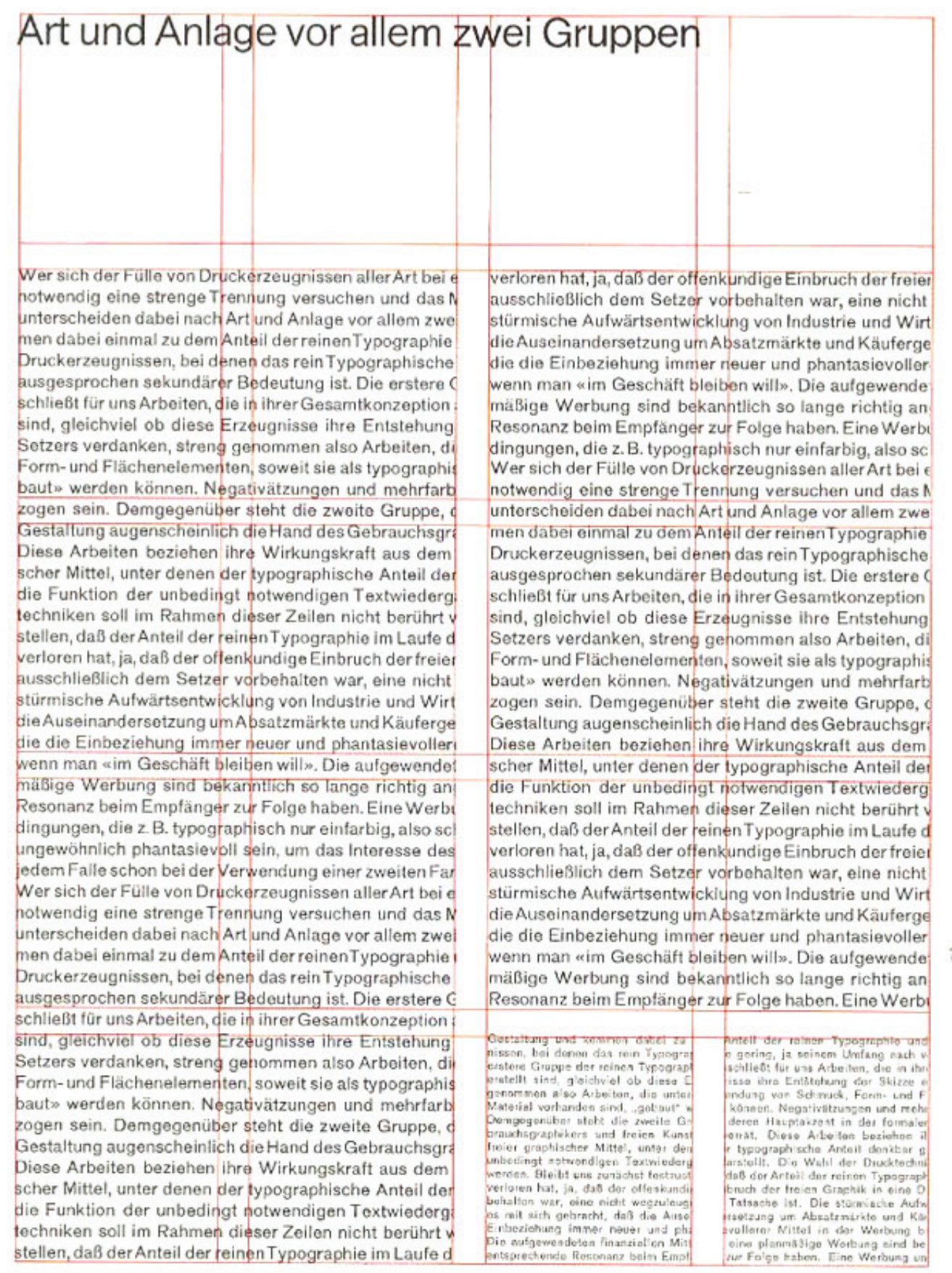

Figura 6. Os sistemas de grid (em vermelho) auxiliam a controlar a tipografia e impor uma ordem na composição da informação. Fonte: Müller-Brockman, 2012 


\section{Considerações: saber e poder na perspectiva interdisciplinar}

A divisão dos saberes e o processo de especialização das ciências ao longo do século XIX e xx não foi um processo isolado da vida cotidiana. Conforme apresenta Foucault, a disciplina se torna cada vez mais presente e estabelece mudanças nas instituições, nas práticas e nos espaços. Para Foucault, o exercício do poder disciplinar está intimamente ligado à constituição de novos saberes. Portanto, a leitura de Sommerman se complementa com o texto de Foucault e permite relacionar o impacto do poder disciplinar tanto na academia como na sociedade, através de um vasto processo de organização funcional e especializada.

Todavia, as mudanças operadas pelo crescente número de técnicas disciplinares e de um racionalismo cada vez mais presente também se refletiram sobre a constituição dos espaços, objetos e os corpos. Conforme apresentado por Foucault, a disciplina opera sobre os corpos e atividades dos indivíduos, treinando-os, moldando-os, tornando-os mais aptos e eficientes. Seja mediante técnicas disciplinares, seja mediante o uso de espaços disciplinares, houve tanto a constituição de uma nova mentalidade quanto a de um novo corpo.

Nesse sentido, consideramos interessante resgatar a importância da religação dos saberes, conforme defende Morin (2002), bem como o discurso de Galeano sobre a separação entre corpo e mente. Isso porque se o saber disciplinar é questionado hoje em diferentes campos e esfera, cabe também discutir a relação desse saber com os espaços que os constituem.

Se os indivíduos ainda são submetidos a uma disciplina corporal, seja pela prescrição de posturas e atos, seja pela imposição do espaço arquitetônico, o ambiente e seus objetos, seria possível constituir uma mentalidade interdisciplinar? É possível religar os saberes sem relacioná-los às práticas cotidianas, aos corpos e aos espaços? É viável estabelecer a interação de disciplinas em salas de aulas diferentes, com espaços, horários e formas de exame diferenciados, segmentados e descontínuos?

As perguntas acima são apenas algumas dentre uma série de questionamentos possíveis na medida em que se começa a pensar as relações entre saber e poder e entre mente e corpo.

A arquitetura e o design tem pesquisado os ambientes de ensino e aprendizagem e há diferentes estudos sobre possíveis melhorias da sala de aula. Em ambas as áreas salienta-se a importância da iluminação e ventilação natural, do posicionamento da escola em um local seguro, do uso de materiais atóxicos e não inflamáveis nas salas de aula, do desenvolvimento de mobiliários ergonômicos, de criação de materiais didáticos e paradidáticos mais adequados, 
entre diversos outros aspectos. Tais estudos têm contribuído para um olhar mais cuidadoso sobre as salas de aula, enfatizando seu papel na aprendizagem considerando-a, como afirma Kowaltowski (2011, p.71) um terceiro professor (o primeiro é o profissional, o segundo é o material didático e o terceiro é o ambiente escolar).

Porém, quando a arquitetura e o design se ocupam de pensar os espaços de ensino, normalmente o fazem sobre alguns pressupostos de ensino ainda marcados pelo poder disciplinar. Isso não significa que estudar os aspectos da saúde, segurança, conforto entre outros não sejam importantes. Mas significa que mesmo sem a intenção, alguns deles acabam reforçando os princípios de ordenação, organização, quadriculamento e exame característicos do poder disciplinar, estimulando uma prática que afirma a separação entre os saberes.

A educação nos campos da arquitetura e do design, por sua vocação interdisciplinar, deveria se preocupar, além dos aspectos pedagógicos, com os aspectos espaciais, mobiliário e os demais objetos para o uso na sala de aula. Mas não (ou não apenas) sob o pretexto de tornar o ambiente mais eficiente e atender melhor as demandas de ensino, pois isso ainda reforça a lógica disciplinar. Se o desejável é incentivar o ensino interdisciplinar, é necessário propor e experimentar outros espaços no qual a interação supere a separação, onde diálogo seja estimulado e não tolhido, onde haja mais estímulos do que censuras.

Cabe, entretanto lembrar das palavras do professor José Luiz Mendes Ripper, ao afirmar que os resultados são frutos da interação entre objetos e ações: "nós designers costumamos nos ocupar dos objetos e damos pouca importância às ações. Não significa que os objetos não sejam importantes, mas as ações são igualmente importantes". (informação verbal) ${ }^{1}$

A partir das palavras de Ripper, é possível pensar que o planejamento dos espaços e objetos é apenas um aspecto para o sonho da interdisciplinaridade. Para que exista, é necessária uma ação conjunta que busque a interação entre as diferentes áreas: pedagogia, psicologia, design, arquitetura, geografia, sociologia, filosofia, medicina, entre outras. Isso porque para uma mudança para um ensino interdisciplinar não bastam projetos pedagógicos, sociopolíticos, filosóficos, arquitetônicos etc. Se esta lógica permanecer os saberes continuarão compartimentados e assim só se criariam objetos desvinculados de ações, ou ideias desvinculadas de corpos. É preciso interagir, buscar ações e objetos conjuntos e assim os resultados serão diferentes. Afinal, como disse Galeano, não somos cabeças que rolam por aí.

1. RIPPER, José Luís Mendes. Comentários realizados durante as aulas da disciplina e Design e Interdisciplinaridade (ART2253) no Programa de pós-graduação em design, Departamento de Artes e Design, PUC-Rio em primeiro de novembro de 2011. 


\section{Referências}

CARVALHO, Ricardo Artur Pereira de; FARBIARZ, Jackeline Lima. Olhares sobre o ensino do projeto em design : gêneros e interações em espaços de ensino e aprendizagem. 2012. 276 f. Tese (Doutorado)-Pontifícia Universidade Católica do Rio de Janeiro, Departamento de Artes e Design, 2012.

CHARTIER, R. A ordem dos livros: leitores, autores e bibliotecas nos séculos XIV e XVIII, Brasília: UNB, 1999.

COUTO, R. Movimento interdisciplinar de designers brasileiros em busca de educação avançada. 1997. 246f. Tese (Doutorado) - PUC-Rio.

DAYRELL, J. A escola como espaço sócio-cultural. In DAYRELL, J. [org.] Múltiplos olhares sobre educação e cultura. Belo Horizonte: UFMG, 1996. p. 136-161

FOUCAULT, Michel. Vigiar e punir: nascimento da prisão. 33. ed. Petrópolis, RJ: Vozes, 2007.

GALEANO, Eduardo. Depoimento na praça Catalunha durante o evento La Acampada, Barcelona, 24/05/11. [vídeo] Disponível em: http://www. youtube.com/watch?feature=player_detailpage $\& v=m d Y 64 T d r i J k \# t=488 \mathrm{~s}$. Acessado em novembro de 2011.

GOULEMOT, Jean Marie. Da leitura como produção de sentidos. In CHARTIER, R. [org.] Práticas de Leitura. Trad. Cristiane Nascimento. São Paulo: Estação Liberdade, 1996. p. 107-116

HARVARD ART MUSEUMS. Bauhaus Building, Dessau, 1925-1926: Second floor plan, 1925-1926. Cambridge: Harvard Art Museums, 2013. Disponível em: http://www.harvardartmuseums.org/art/197711. Acesso em: maio 2014. HfG-ARCHIV ULM. Objetcts. Ulm: HfG-Archiv Ulm. Disponível em: http:// www.hfg-archiv.ulm.de/english/the_collections/hfg_collection/objects_ photos.html. Acesso em: maio de 2014.

KOWALTOWSKI, Doris .C.C.K., Arquitetura escolar: o projeto do ambiente de ensino, São Paulo: Oficina de Textos, 2011.

MÜLLER-BROCKMANN, Josef. Sistemas de grelhas: um manual para designers gráficos. $3^{\text {a }}$ ed. [Trad. Paulo Heitlinger] Barcelona, Gustavo Gili; edição bilíngue [espanhol e português de Portugal], 2012. 
MORIN E.; ALMEIDA, M.C; CARVALHO, E.A. (ORGS.). Educação e Complexidade: os Sete Saberes e outros ensaios. São Paulo. Cortez, 2002.

SOMMERMAN, Américo. Inter ou transdisciplinaridade? da fragmentação disciplinar ao novo diálogo entre os saberes. São Paulo: Paulus, 2006.

DE STEFAnI, P. An Emancipatory Practice of Architecture? (Draft). Disponível em: http://artificialorder.wordpress.com/2011/12/14/an-emancipatory-practice-of-architecture . Acesso em: maio 2014.

WIKIPEDIA. Haussmann's renovation of Paris. [s/l] [s/d] Disponível em: http://en.wikipedia.org/wiki/Haussmann\%27s_renovation_of_Paris. Acesso em: maio 2014. 
Recebido em: 03/05/2014

Aceito em: 01/06/2014

\section{Como citar}

CARVALHO, Ricardo Artur; FABIARZ, Jackeline Lima. A disciplina na sala de aula: arquitetura e design como afirmação de concepções de ensino aprendizagem. Arcos Design. Rio de Janeiro: PPD ESDI - UERJ. Volume 8 Número 1 Junho 2014. pp. 96-113. Disponível em: [http://www.e-publicacoes.uerj.br/ index.php/arcosdesign]

\section{DOI}

http://dx.doi.org/10.12957/arcosdesign.2014.13928

\section{(c) (1) (2)}

A Revista Arcos Design está licenciada sob uma licença Creative Commons Atribuição - Não Comercial - Compartilha Igual 3.0 Não Adaptada. 